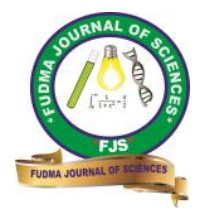

FUDMA Journal of Sciences (FJS)

ISSN online: $2616-1370$

ISSN print: 2645 - 2944

Vol. 4 No. 3, September, 2020, pp $323-327$

DOI: https://doi.org/10.33003/fjs-2020-0403-335

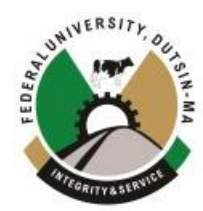

\title{
EVALUATION OF THE IMPACT OF PLASMID CURING ON ANTIBIOTIC RESISTANCE ON SOME CLINICAL ISOLATES OF ESCHERICHIA COLI
}

\author{
*15ulaiman, M. A., ${ }^{1}$ Muhammad H. S., ${ }^{1}$ Aliyu, M. S., ${ }^{2}$ Ibrahim, A ${ }^{1}$ Hussaini, I. M and ${ }^{1}$ Anchau, Z. G. \\ ${ }^{1}$ Department of Microbiology, Faculty of Life Sciences, Ahmadu Bello University, Zaria, Kaduna State, Nigeria \\ ${ }^{2}$ Department of Medical Laboratory Science, Bayero university, Kano State, Nigeria \\ Corresponding Author’s email: masulaiman@abu.edu.ng/ +2348038937309
}

\begin{abstract}
Multidrug resistance (MDR) exhibited by some strains of Escherichia coli may be due to acquiring mobile genetic element (R-plasmid) by the bacteria, or intrinsically induced by inappropriate use of antibiotics by the hosts. Infection by such strains may result to prolonged illness and greater risk of death. The study evaluated the impact of curing on antibiotic resistance on selected clinical isolates of $E$. coli. Twenty clinical isolates of E. coli from our previous studies were re-characterized using conventional microbiological techniques. Antibiotic sensitivity testing was determined by disk diffusion method, MDR selected based on resistance to $\geq 2$ classes of antibiotics. Multiple antibiotic resistance (MAR) index was determined as ratio of the number of antibiotic resisted to the total number of antibiotics tested and considered significant if $\geq .0 .2$. The isolates that showed significant MAR index were subjected to plasmid curing using acridine orange, thereafter, profiled for plasmid and the cured ones were re-tested against the antibiotics they initially resisted. Out of the 20 isolates, $19(95 \%)$ were confirmed as E. coli, all (100\%) of which were MDRs, which was highest against augmentin (78.9\%) followed by amoxacillin (52.6\%). However, after the plasmid curing only $6(31.6 \%)$ out of the 19 isolates cured retained significant MAR index and the level of the significance had reduced drastically in $16(84.2 \%)$ isolates. Conclusively, curing assay can completely eliminate R-plasmid acquired resistance. More studied on plasmid curing agents for possible augmentation of the agents into antibiotics may see the rise of successful antibiotic era again.
\end{abstract}

Keywords: Plasmid curing, Multidrug Resistance, Acridine orange, Escherichia coli.

\section{INTRODUCTION}

Globally, there is an emergence of a new trend of antibacterial resistance against commonly used antibiotics (Giwa et al., 2019; Abdullahi et al., 2016). Antibacterial resistance (ABR) occurs when bacteria adapt and become less susceptible to drugs that were previously effective against them (Amer et al., 2018). Emergence of antimicrobial resistance is considered one of the major health threat affecting humans, worldwide (Duedu et al., 2017; Rogers et al., 2012). The resistance may be classified into intrinsic, arising from the inappropriate use of antibiotics, interaction of bacteria with natural antibacterial compounds in the external environment or may arise from natural selection. The second type is classified as acquired resistance, which results from exchange of genetic resistance element such as plasmids, integrons or transposons (Duedu et al., 2017; Sakumi et al., 2013). Plasmids are extra chromosomal piece of double stranded circular DNA which has the capability to replicate independent of the host chromosome, yet coexist with it. Resistance plasmids (R plasmids) have been reported to be the most frequent cause of antibiotic resistance in most bacteria including the $E$. coli which have exhibited resistance to different antibiotics such as beta lactam antibiotics, aminoglycosides and fluoroquinolone (Carattoli, 2013; Zhang et al., 2014). They allow the movement of genetic materials including antimicrobial resistant genes between bacterial species and genera through gene exchange processes thereby causing a rapid spread of the antibiotic resistance (Carattoli, 2013; Daneman et al., 2013). The plasmid associated resistance can be gotten rid of by plasmid curing, which occurs spontaneously during bacterial cell division or by treating the bacteria with some physical or chemical reagents such as acridine orange or ethidium bromide (Elias $e t$ al., 2013). The reagents can cause a single nick in the plasmid, thereby, initiating its relaxation and subsequently affects its replication. Application of the curing assay may help to mitigate the spread of the antibiotic resistance encoded by Rplasmid. (Letchumanan et al., 2015; Burussow et al., 2004), consequently stops the spread of the antibiotic resistance. The study aimed at determining the impact of curing on eliminating antibiotic resistance on selected clinical isolates of E. coli.

\section{MATERIALS AND METHODS}

Collection of Isolates

Twenty (20) isolates of E. coli from faecal samples of gastroenteritis patients were obtained from our_previous studies (Sulaiman, et al., 2019) on nutrient agar slants and coded HM1 to HM20.

\section{Re-characterization of the Isolates}

The isolates were sub-cultured aseptically by streaking on Eosine Methylene Blue (EMB) agar plates and incubated overnight at $37^{\circ} \mathrm{C}$. The colonies presumed to be E. coli were preliminarily_characterized by Gram staining technique and observed under a microscope at $100 \mathrm{X}$ objective lens (Cheesebrough, 2009). The isolates were further subjected to some biochemical tests including Methyl Red (MR)-VogesProskauer (VP) by inoculating the MR-VP broth (Oxoid) with a pure colony and incubated at $37^{\circ} \mathrm{C}$; after $24 \mathrm{hrs} 1 \mathrm{ml}$ of the inoculated broth was aseptically transferred into a test tube (to have 2 tubes for the 2 tests). For the MR test, 5 drops of methyl 
red was added and for the VP test 3 drops of $6 \%$ alpha napthol and 1 drop of $40 \%$ potassium hydroxide were added and the reaction was observed. Additionally, indole test was carried out, where a colony was inoculated into peptone water and incubated at $37^{\circ} \mathrm{C}$ for 24 hours, and then $0.5 \mathrm{ml}$ of Kovac's reagent was added and the reaction was observed. Finally, the isolates were tested for their ability to utilize citrate as the soul carbon source, by streaking a pure discreet colony from the overnight cultures of the respective isolates, on to Simmon's citrate agar slants, and were incubated at $37^{\circ} \mathrm{C}$ for 24 hours, before the colour change was observed (Cheesebrough, 2009). The isolates were stored on slants under refrigeration $\left(4^{0} \mathrm{C}\right)$ for further analysis and reference.

\section{Antibiotic Sensitivity Assay of Bacterial Isolates}

Isolates were subjected to antibiotics screening by disk diffusion method as described by the Clinical and Laboratory Standards Institute (CLSI). Inocula were prepared by suspending overnight cultures in sterile normal saline and the turbidity of the suspensions were adjusted to $0.5 \mathrm{McFarland}$ scale. Then, $0.1 \mathrm{~mL}$ of the standardized bacterial suspension was then spread on to Mueller Hinton agar plates and allowed for absorption before the antibiotic disks were placed on the plates and incubated overnight at $37^{\circ} \mathrm{C}$. The six antibiotics used were augmentin $(30 \mu \mathrm{g})$, amoxacillin $(30 \mu \mathrm{g})$, ciprofloxacin $(10 \mu \mathrm{g})$, gentamycin $(10 \mu \mathrm{g}), \quad$ streptomycin $(30 \mu \mathrm{g})$ and trimethoprim/sulfamethoxazole $(30 \mu \mathrm{g})$. The sensitivity pattern was determined by interpreting the zone of inhibition around each disk according to the CLSI (CLSI, 2018) manual. The MAR index was calculated as the ratio of number of antibiotic resisted to the total number of antibiotic tested, and interpreted as significant if the ratio $\geq 0.2$ and insignificant if the MAR index $<0.2$ (Masterton, 2008)

\section{Plasmid Curing Assay}

Isolates showing MDR (i.e. resistance to at least 2 classes of antibiotics) were selected for plasmid curing assay. The curing assay was carried out by aseptically mixing $0.5 \mathrm{ml}$ of acridine orange solution with $1 \mathrm{ml}$ of Mueller Hinton broth, each in a sterilized test tube. A pinch of the pure colony of each MDR isolates was inoculated into the test tube containing the mixture and then agitated carefully and incubated overnight at $37^{\circ} \mathrm{C}$ From each of the plasmid curing aliquots, a loopful was streaked aseptically, onto a freshly prepared Brain Heart Infusion agar plate and incubated overnight at $37^{\circ} \mathrm{C}$ (Zhang, et

\section{RESULTS}

Out of the 20 isolates obtained, 19 (95\%) were non-mucoid with green metallic sheen, Gram negative rods, MR and indole positive, VP and citrate negative, therefore were reconfirmed as E. coli.

Out of the 19 isolates confirmed, $15(78.9 \%)$ were resistant against augmentin (78.9\%), 10(52.6) were resistant each against amoxicillin (52.6\%) and ciprofloxacin. On the other hand, highest activity was shown by streptomycin (89.5\%), followed by gentamicin (68.4\%) and trimethoprim/sulfamethoxazole (63.2\%), Table 1.

Additionally, from the current findings significant MAR index $(\geq 0.2)$ was observed in all the 19 isolates $(100 \%)$. However, the level of the significance varied, ranging from $0.33(52.6 \%)$ to

\section{al., 2012; Olukoya and Oni, 1990).}

\section{Screening the isolates for Plasmid after the Curing Assay} A colony was picked from the Brain Heart Infusion cultures of the isolates and inoculated into the a $200 \mu 1$ solution containing $100 \mathrm{mM}$ glucose, 50mM Tris hydrochloride $(\mathrm{pH} 8), 10 \mathrm{mM}$ EDTA. The mixture was incubated at $37^{\circ} \mathrm{C}$. The mixture was then treated with $50 \mu 1$ lysozyme, $400 \mu$ l of $1 \%$ sodium dodecyl sulphate in $0.2 \mathrm{~N} \mathrm{NaOH}$. Lastly, $300 \mu \mathrm{l}$ of $30 \%$ potassium acetate was added and were incubated in ice for $5 \mathrm{~min}$ and then centrifuged at 5000RPM for $5 \mathrm{~min}$. the supernatant was pipetted out and mixed with equal volume of isopropanol and allowed for $5 \mathrm{~min}$. Then $100 \mu \mathrm{l}$ was pipetted carefully from the upper part of the supernatant into another eppendorf tube and used as the plasmid. The extracted plasmid $(10 \mu 1)$ was casted into $1 \%$ agarose gel, containing ethidium bromide as the intercalating dye and allowed to run for $30 \mathrm{~min}$ under electrophoresis. The gel was examined under UV light documentation system (BioDoc-It ${ }^{\mathrm{TM}}$ ) for bands (above 500bp) (Olukoya and Oni, 1990).

\section{Determination of Isolates for Antibiotics Susceptibility Pattern after Plasmid Curing}

From the slants of the isolates that did not yield plasmid, a loopful was streaked aseptically onto a freshly prepared nutrient agar plates and incubated overnight at $37^{\circ} \mathrm{C}$. Subsequently, from the culture plates suspensions were prepared in sterilized normal saline and standardized to 0.5 McFarland scale. Then, $0.1 \mathrm{ml}$ of the standardized inocula were spread each onto Mueller Hinton agar plate and the antibiotics resisted previously by the isolates were seeded on to the plates at a distance of $15 \mathrm{~mm}$ apart from each other and then incubated at $37^{\circ} \mathrm{C}$ for 24 hours. The zone of inhibition around the antibiotic discs were recorded and interpreted sensitive, intermediate and resistance according to the Clinical Laboratory Standard Institute (CLSI) manual (CLSI, 2018).

\section{Determination of Multiple Antibiotic Resistance (MAR) Index after Curing}

The MAR index was determined again after the curing assay, as the ratio of the number of antibiotic resisted to the total number of antibiotic tested, and interpreted as significant if the ratio $\geq 0.2$ and insignificant if the MAR index $<0.2$ (Masterton, 2008)

0.67 (15.8\%), Table 2.

The curing was successful in all the $19(100 \%)$ isolates that showed significant MAR index, with no plasmid observed in any isolate after the plasmid curing assay (Plate I). After the curing assay, only $6(31.6 \%)$ out of the 19 isolates cured showed significant MAR index of 0.33 (Table 3), and the level of significance of the MAR index reduced drastically, in 16 $(84.2 \%)$ out of the 19 isolates (Table 2 and Table 3 ).

Finally, antibiotic resistance against augmentin was found to be significantly plasmid mediated, while that against gentamicin and ciprofloxacin was entirely plasmid mediated. Meanwhile the resistance against amoxicillin and trimethoprim/sulfamethoxazole was significantly non-plasmid mediated, the resistance against ciprofloxacin was equally plasmid and non-plasmid mediated (Table 4). 
Table 1: Antibiotic Susceptibility Pattern of Clinical Isolates of Escherichia coli.

\begin{tabular}{lcll}
\hline & $\begin{array}{c}\text { Antibiotic (conc.in } \boldsymbol{\mu g}) \\
\text { No. susceptible (\%) }\end{array}$ & $\begin{array}{l}\mathbf{N = 1 9} \\
\text { No. intermediate (\%) }\end{array}$ & $\begin{array}{l}\text { Sensitivity Pattern } \\
\text { No. resistant (\%) }\end{array}$ \\
\hline Augmentin (30) & $4(21.1)$ & $0(0)$ & $15(78.9)$ \\
Amoxacillin (30) & $7(36.8)$ & $2(10.5)$ & $10(52.6)$ \\
Ciprofloxacin (10) & $8(42.1)$ & $1(5.3)$ & $10(52.6)$ \\
Gentamycin (10) & $13(68.4)$ & $0(0)$ & $6(31.6)$ \\
Streptomycin (30) & $17(89.5)$ & $0(0)$ & $2(10.5)$ \\
Trimetho./ Sulfamettho.(30) & $12(63.2)$ & $0(0)$ & $7(36.8)$ \\
\hline
\end{tabular}

Table 2: Antibiotic Resistance Pattern of Clinical Isolates of E. coli before Plasmid Curing

\begin{tabular}{llll}
\hline Isolate code & No. of Antibiotic Resisted & Resistance Pattern & MAR Index \\
\hline HM2 & 3 & AM, CPX, S, & 0.5 \\
HM3 & 2 & AU, AM & 0.33 \\
HM4 & 3 & AU, AM. CPX & 0.5 \\
HM5 & 3 & AM, CN, SXT & 0.5 \\
HM6 & 2 & AM, CPX & 0.33 \\
HM7 & 4 & AU, CN, S, SXT & 0.67 \\
HM8 & 2 & AU, CPX & 0.33 \\
HM9 & 3 & AU, AM, SXT & 0.5 \\
HM10 & 4 & AU, AM, CPX, CN & 0.67 \\
HM11 & AU, CPX, SXT & 0.5 \\
HM12 & 3 & AU, AM & 0.33 \\
HM13 & 2 & AU, SXT & 0.33 \\
HM14 & 3 & AU, CPX & 0.33 \\
HM15 & AU, CPX & 0.33 \\
HM16 & 2 & AU, CPX & 0.33 \\
HM17 & 2 & AU, CPX & 0.33 \\
HM18 & 2 & AU, SXT, CN, & 0.5 \\
HM19 & 3 & AU, AM, CN, SXT & 0.67
\end{tabular}

Keygs: AU =Augmentin, $\mathrm{CN}=$ Gentamicin, $\mathrm{CPX}=$ Ciprofloxacin, $\mathrm{AM}=$ Amoxacillin, $\mathrm{S}=$ Streptomycin, $\mathrm{SXT}=\mathrm{Trimethoprim} /$ Sulfamethoxazole, MAR= Multiple antibiotic resistance

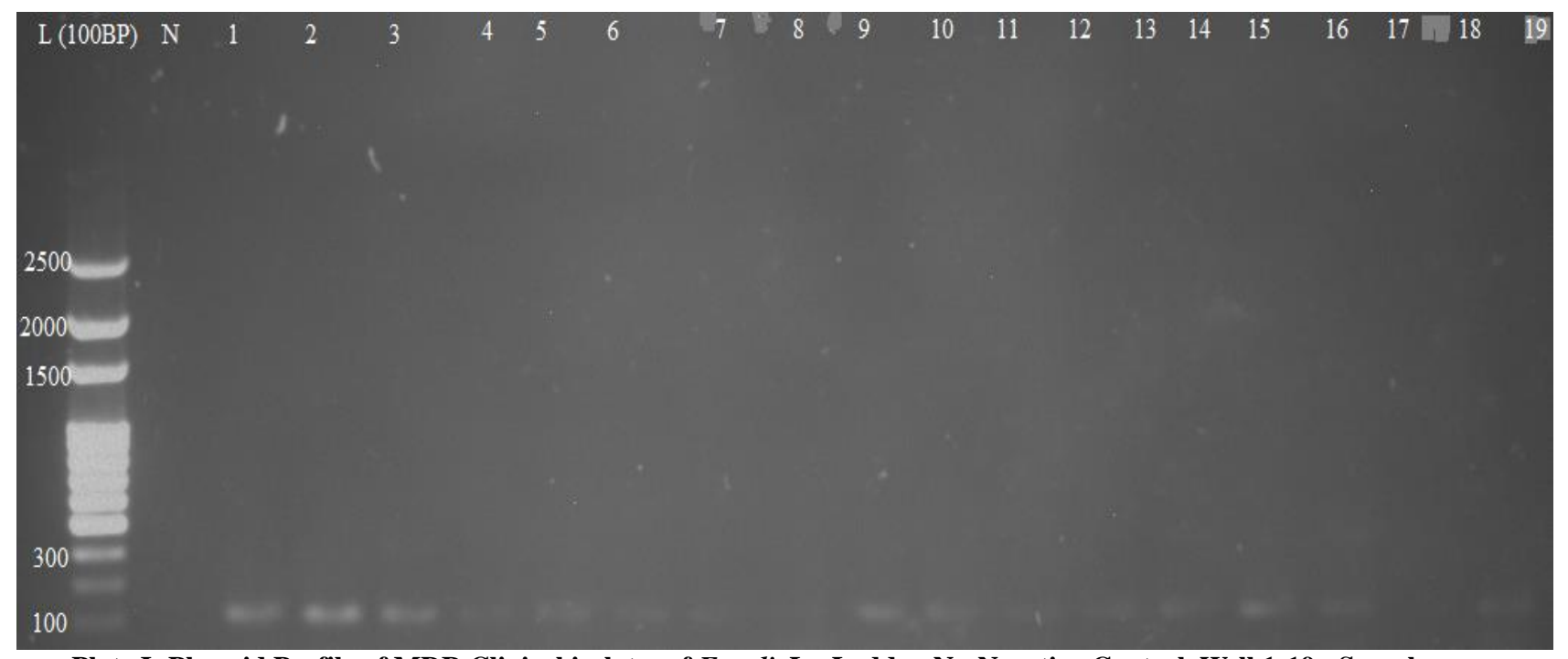

Plate I: Plasmid Profile of MDR Clinical isolates of $E$. coli. $\mathrm{L}=$ Ladder, N= Negative Control, Well 1-19= Samples. 
Table 3: Antibiotic Resistance Pattern of Clinical Isolates of E. coli after Plasmid Curing

\begin{tabular}{llll}
\hline Isolate code & No. of Antibiotic Resisted & Resistance Pattern & MAR Index \\
\hline HM2 & 2 & AM, CPX, & 0.33 \\
HM3 & 2 & AU, AM & 0.33 \\
HM4 & 0 & - & 0 \\
HM5 & 1 & SXT & 0.17 \\
HM6 & 2 & AM, CPX & 0.33 \\
HM7 & 2 & AU,SXT & 0.33 \\
HM8 & 0 & - & 0 \\
HM9 & 1 & AM & 0.17 \\
HM10 & 2 & AM, CPX & 0.33 \\
HM11 & 1 & SXT & 0.17 \\
HM12 & 2 & AU, AM & 0.33 \\
HM13 & 1 & SXT & 0.17 \\
HM14 & 0 & - & 0 \\
HM15 & 1 & CPX & 0.17 \\
HM16 & 1 & CPX & 0.17 \\
HM17 & 0 & - & 0 \\
HM18 & 1 & SXT & 0.17 \\
HM19 & 1 & SXT & 0.17
\end{tabular}

KEYS: AM-Amoxacillin, AU-Augmentin, CPX-Ciprofloxacin, CN-Gentamycin, S-Streptomycin, SPX-

Trimethoprim/Sulfamethoxazole, MAR-Multiple antibiotic resistance.

Table 4: Effect of Curing in Combating Multidrug Resistant Clinical Isolates of E. coli after Curing

\begin{tabular}{llll}
\hline Antibiotic & No. Cured resistance (\%) & No. Persistent resistance (\%) & \% Ratio \\
\hline Augmentin & $12(80)$ & $3(20)$ & 0.25 \\
Amoxicillin & $4(40)$ & $6(60)$ & 1.5 \\
Ciprofloxacin & $5(50)$ & $5(50)$ & 1 \\
Gentamicin & $6(100)$ & $0(0)$ & 0 \\
Streptomycin & $2(100)$ & $0(0)$ & 0 \\
Trimetho./ Sulfametho. & $1(14.3)$ & $6(85.7)$ & 6.0
\end{tabular}

Interpretation: \% Ratio of $>1$ shows that the resistance to the antibiotic was largely genome mediated while $\%$ Ratio of $<1$ was largely plasmid mediated.

\section{DISCUSSION}

From our findings, highest level of antibiotic efficacy was observed to stereptomycin, gentamicin and trimethoprim/sulfamethoxazole; perhaps, because both stereptomycin and gentamicin are administered by injection (intravenous/intramuscular) and trimethoprim sulfamethoxazole has not been commonly administered in treatment of infections cause by Gram negative bacteria. Such efficacy was not observed in the case of augmentin, amoxacillin and ciprofloxacin, which may either be due to harbouring of some genetic elements (plasmids, transposons and integrons) been associated with resistance or inappropriate use of antibiotics (Oriomah and Akpe, 2019).

The significant MAR index recorded against all the isolates used in the study, highlighted the terrible future awaiting the antibiotic era, unless some scientific approaches are put in place to curtail such public health hazard. However, the plasmid curing assay employed in our study may be one of such scientific approaches that may help to reduce the spread of antibiotic resistance in bacteria. This is because after the curing, significant MAR index was completely corrected in $68.4 \%$ and drastically reduced in $15.8 \%$ of the studied isolates. This is in agreement with the previous findings on impact of plasmid curing on multidrug resistant E. coli (Oriomah and Akpe, 2019; Zaman et al., 2010), Pseudomons aeruginosa (Elias et al., 2013), Vibrio species (Zhang, et al., 2012).
The role of the curing on reverting the antibiotic multidrug resistance depends on whether the resistance is acquired or induced (Duedu et al., 2017), The complete elimination of resistance against gentamycin and streptomycin by curing, suggests that the resistance is acquired, confirming further that the efficacy of antibiotics administere by injection is easily conserved (Sulaiman and Rufa'I, 2019; Guillermo et al., 2012), perhaps why the curing did not show a significant impact on resistance against the antibiotics administered orally as trimethoprim/sulfamethoxazole and amoxiciiln, as such the resistance observed against them may be due to inappropriate use of the antibiotics (DeSmet et al., 2011).

\section{CONCLUSION}

From our findings, treatment of $E$. coli associated infection may be a serious challenge, as it is becoming multiply resistant to the commonly used antibiotics. However, plasmid curing can significantly reduce or completely eliminate antibiotic resistance, especially against the antibiotic administered through intramuscular/intravenous injection. On the other hand, inappropriate use of antibiotic may be the major cause of resistance against the antibiotics administered orally.

\section{RECOMMENDATION}

The policy that prohibits indiscriminate use of antibiotics should be 
fully implemented. More studies should be carried out on plasmid curing agents, to evaluate the possibility of making them a part of the ingredients used in preparing antibiotics.

\section{REFERENCES}

Abdullahi, H.O, Maryam, A., and Machido,D.A. (2016). Isolation and Characterization of Escherichia coli O157in human stool samples from parts of Kaduna Metropolis Nigeria. American Journal of Food Science and Technology, 5:125-128.

Amer, M.M., Mekky, H.M., Amer, A.M. and Fedawy, H.S. (2018). Antimicrobial resistance genes in pathogenic Escherichia coli isolated from diseased broiler chickens in Egypt and their relationship with the phenotypic resistance characteristics, Veterinary World, 11(8): 1082-1088

Burrssow, H.H.Canchaya, C. and Herdt, W. (2004). Phages and Evolution of the Bacteria Pathogen: from genomics rearrangement to Lysogenic conversion. Journal of Microbiology and Molecular Biology Revision, 68:560-602.

Carattoli, A. (2013). Plasmid and the spread of resistance. International Journal of medical microbiology, (303):298-304.

Cheesebrough M. (2009). District Laboratory Practice in Tropical Countries. Cambridge University Press, $2^{\text {nd }}$ ed., 96-97.

Elias, H.M., Qader, M.K. and Saleh and W.M. (2013). Determination of Plasmid DNA Role in Multidrug Resistant Pseudomonas aeruginosa Clinical Isolates. International Journal of Microbiology and Immunology, 1: 80-86.

Letchumanan, V., Chan, K. and Lee, L. (2015). An insight of Traditional Plasmid curing in Vibrio species. Frontiers in microbiology. http://doi.org/10.3389/fmicb.2015.00735

Daneman, N., Sarwar, S., Fowler, R.A., Cuthbertson, B.H. (2013). Effects of selective decontamination on antimicrobial resistance in intensive care units. Lancet Infectious Disease, 13:328-341.

DeSmet, A.M., Kluytmans, J.A., Blok, H.E., Mascini, E.M., Benus, R.F, Bernards,A.T. (2011). Selective digestive tract decontamination and antibiotic resistance in patients in intensive care units. The Lancet, 11:372-380

Duedu, K.O., Offei, G., Codjoe, F. S. and Donkor, E.S. (2017). Multidrug Resistant Enteric Bacterial Pathogens in a Psychiatric Hospital in Ghana: Implications for Control of Nosocomial Infections. International Journal of Microbiology, https://doi.org/10.1155/2017/9509087

Giwa, F.J., Ige, O.T., Haruna, D.M., Yaqub, Y., Lamido, T.Z. and Usman, S.Y. (2018). Extended-Spectrum beta-lactamase production and antimicrobial susceptibility pattern of uropathogens in a Tertiary Hospital in Northwestern Nigeria. Annals of Tropical Pathology, 9:11-6.
Guillermo, V.S., Ronald, N.M. and Jose, M.B. (2012). In vitro antimicrobial resistance of urinary Escherichia coli isolates among U.S outpatients from 2000-2010. Antimicrobial Agents and Chemotjerapy,56(4):2181-2183

Kasumi, I., Tazumi, S., Furuya, N., Komano, T. (2013). Exclusion A proteins of Inc1 plasmid R64 and Inc1y plasmid R621 a recognize different segments of their cognate Tra $\mathrm{Y}$ proteins in entry exclusion plasmid, Springer, 69:138-145

Masterton, R. G., Galloway, A., French, G., Street, M., Armstrong, J., Brown, E., Cleverley, J., Dilworth, P., Fry, C., Gascoigne, A. D., Knox, A., Nathwani, D., Spencer, R. and Wilcox, M. (2008). Guidelines for the management of hospital-acquired pneumonia in the UK: Report of the Working Party on Hospital-Acquired Pneumonia of the British Society for Antimicrobial Chemotherapy. Journal of Antimicrobial Chemotherapy, 62(2) https://doi.org/10.1093/jac/dkn162v

Olukoya, D.K. and Oni, O. (1990). Plasmid Profile Analysis and Antimicrobial Susceptibility Patterns of shigella isolates from Nigeria. Epidemiology and Infection, 105:59-64

Oriomah, C., Akpe, A.R. (2019). Plasmid curing of antibiotic resistant Escherichia coli isolates from urine and stool samples. Journal of Microbiology and Antimicrobials, 11:1-4.

Rogers, B.A., Kennedy, K.J., Sidjabat, H.E., Jones, M., Collignon, P. and Paterson, D.I. (2012). Prolonged, carriage of resistant E. coli by returned travelers. European Journal of Clinical Investigation, 13:328-341

Sulaiman, M.A. and Usman, A. R. (2020). Assessment of Potential Efficacy of Coliphage

Therapy on Multidrug Resistant Clinical Isolates of Escherichia coli. UMYU Journal of Microbiology Research,5 (1)49-53.

Sulaiman, M.A., Aminu, M., Ella, E.E. and Abdullahi, I.O. (2020). Characterization of

Escherichia albertii, Shigella species and Diarrhoeagenic Escherichia coli from stool samples of gastroenteritis patients in Nano state, Nigeria. Ph.D Thesis, Department of Microbiology, Ahmadu Bello university, Zaria.

Wayne, P.A (2018). CLSI Performance Standards for Antimicrobial Susceptibility Testing. $28^{\text {th }}$ ed. CLSI supplement M100. Clinical and Laboratory Standards Institute

Zaman, M.A, Pasha, M.H. and Akhter, M.Z. (2010). Plasmid curing of Escherichia coli cells with ethidium bromide, sodium dodecyl sulfate and acridine orange. Bangladesh Journal of Microbiology,27(1):28-31.

Zhang, R., Pan, L., and Zhao, Z.(2012). High Incidence of plasmid in marine Vibrio species isolated from Mai po Nature Reserve of Hong Kong. Ecotoxicology, 21 (6):1661-1668 